\title{
NARRATIVA EM WALTER BENJAMIN: OS PROBLEMAS DA HISTÓRIA, DA CULTURA E DA CONTEMPORANEIDADE
}

Hedgar Lopes Castro

\begin{abstract}
RESUMO
O presente artigo apresenta uma leitura da concepção de Walter Benjamim sobre o declínio da experiência e da narração na modernidade, a partir das obras A Crise do Romance, Experiência e Pobreza e O Narrador. De acordo com essa concepção, a história já não é autenticamente do homem, que na atualidade está limitado à relação técnica e capitalista, o que eclipsa a tradição. Em consequência, a sua cultura vem se empobrecendo, pois mergulhada unicamente no presente desde a modernidade, no qual reina o uso limitado de potencialidades humanas que interessa ao capitalismo. Isso se inicia no fim da modernidade, com o declínio da narrativa tradicional e a emergência do romance, embora este não seja entendido por Benjamin como o fim daquela. A criação e recriação permanentes da história, que se sucedia com a narrativa clássica, dão lugar a um mundo onde a sabedoria e a memória são conservadas exclusivamente na medida em que reverbera o presente vivido contemporaneamente.
\end{abstract}

Palavras-chave: Romance. Narração. História. Cultura. Memória.

\section{NARRATIVE IN BENJAMIN WALTER: THE HISTORY OF PROBLEMS OF CULTURE AND CONTEMPORARY}

\begin{abstract}
The presente article presents a reading of the conception of Walter Benjamin about the decline of the experience and the narration in the modernity, from the works The Crisis of the Romance, Experience and Poverty and The Narrator. According to this conception, the history not anymore is authentically of the man, that in the present is limited to the relation technique and capitalist, what eclipses the tradition. In consequence, his culture comes being formed in way more and more impoverished, therefore dived only into the present since modernity, in which reigns the limited use of human potentialities that interests the capitalism. This is initiated in the end of modernity, with the decline of the traditional narrative and the emergency of the romance, although this is not understood by Benjamin as the end of that. Thus, the permanent creation and
\end{abstract}


recreation of the history that was succeeded with the classic narrative give place to a world where the wisdom and the memory is conserved exclusively as far as it reverberates the present contemporarily lived.

Keywords: Romance. Narration. History. Culture. Memory.

\section{Introdução}

A primeira obra abordada nesse estudo é A Crise do Romance (1930), para destacar em que sentido o romance se distancia da narrativa e amesquinha a experiência e a história. Para tal abordagem, partir-se-á da seguinte questão: por que e em que aspectos o romance difere da narrativa? A segunda etapa pauta-se em duas obras, que se assemelham, se continuam e se complementam em suas críticas e temáticas: Experiência e Pobreza (1933) e O Narrador (1936). Elas destacam que a narrativa, sem poder mais expressar a experiência, se encontra em extinção, acrescentando-se a isso que a própria formação dos indivíduos funda-se no declínio, dentro de uma cultura que se transformou em barbárie (BENJAMIN, 1985, 115). Tratar-se-á dele a partir da seguinte questão: em que sentido a criatividade humana está reduzida, na perspectiva benjaminiana, à pobreza da experiência? Pretende-se analisar, primeiro, a criatividade do homem que é impedida, permanentemente, na relação entre a narrativa e o seu ouvinte, frente ao cotidiano capitalista atual que se the defronta; segundo, sobre a morte da capacidade, no romance, de experienciar e narrar uma história limitada especialmente ao presente.

Mais precisamente, Benjamin trata de uma perda peculiar, outrora fundamental para a experiência da história que o homem faz e pode infinitamente refazer. É a perda da experiência que não pode mais ser dita e observada como a história do próprio homem; é a perda da sabedoria como fonte fundamental para resgatar o passado, atualizá-lo,, sendo esta sabedoria não só algo objetivado e nobre, mas, sobretudo, como sendo a sua capacidade de recolher o que vivencia e culturalmente produzir seu movimento histórico, o que deveria fazer a partir de si mesmo e, nessa medida, autenticamente. Como 
na época capitalista isso já não se verifica, nem no senso prático, nem na capacidade de memorizar dos homens, a realidade assim diagnostica-se, segundo o fenômeno onde, de acordo com Benjamin: "[...] a arte de contar torna-se cada vez mais rara porque ela parte, fundamentalmente, da transmissão de uma experiência do sentido pleno, cujas condições de realização já não existem na sociedade capitalista moderna" (BENJAMIN, 1985, 10).

\section{História e experiência: dois declínios, individual e culturalmente}

Benjamin inicia o seu artigo $A$ Crise do Romance fazendo uma alusão crítica à poesia épica, sendo ela condutora e promotora da solidão humana. A consequência imediata disso é a produção, no romance, de uma ferramenta que o faz disperso de si mesmo para, por exemplo, dar conselhos a outrem (BENJAMIN, 1985, 54). Pode-se ver Benjamin, nessa passagem, já disposto a tratar do que mais tarde desenvolveria sobre a questão do sábio que aconselha, muito distante da dimensão romancista que se limita a descrever a experiência humana de modo a levar o homem ao sofrimento sentimental, não passando de um desgarrado de si mesmo. Benjamin lembra que a epopeia de Homero ou Dante - obras clássicas - foram baseadas na oralidade, não havendo relação nenhuma com o gênero do romance, gerado e fruído na solidão, e desligado da narrativa que preserva o caráter puro da poesia épica. Ao invés disso, o gênero romance precisa do livro para se estabelecer, renegando, assim, a tradição oral. Ele mata a espontaneidade do espírito, por estar envolto a temáticas que não pressupõem a menor andança espiritual como a narrativa o pressupõe.

A narrativa, como sendo preservadora dos traços originais da poesia épica, contrapõe-se ao romance, que não realiza esta tarefa e com ela não se preocupa. Benjamin apresenta a obra romanesca de André Gide, para mostrar que as personagens estabelecem relações voltadas ao indivíduo e alheias à exterioridade, ao mundo; assim configurada, essa obra estabelece-se como 
uma antítese da atitude épica que se acha na narrativa (BENJAMIN, 1985, 56). Benjamin elege como um dos maiores críticos dessa concepção romancista um escritor chamado Döblin, que reagirá veementemente contra essa característica do romance; pois ele é um defensor da prática narrativa por meio da exposição de acontecimentos e da realização de reflexões. A montagem é aquilo de que se serve Alfred Döblin em sua obra, para elaborar a narrativa; trata-se de uma montagem constituída de histórias escandalosas, canções populares, anúncios de várias ordens; mas essas e outras montagens são baseadas em documentos, não na própria arbitrariedade. Seu método é acompanhar as personagens lentamente, sem pressa de fazê-los falar, apenas prevendo o que pode acontecer, sem espantos ou sustos com o acaso. Döblin reproduz com maestria o modo como era feita a narração classicamente, ressaltando a total despreocupação do narrador com detalhes meramente psicológicos, como sentimentos ou ainda dados históricos, mas com o movimento da narrativa e com a sua criatividade. A contraposição direta disso é o romance, onde a existência já traçada, na história apresentada, trava ou tolhe a perspectiva de refazer permanentemente a história. Isso deflagra a falta absoluta de capacidade de fazer da história do ser humano um patrimônio ou dar a ela o valor devido, como se verá com mais clareza em outro texto de Benjamin: Experiência e pobreza.

Benjamin inicia o ensaio de 1933 lembrando e ressaltando a perda da experiência e do valor da tradição; a falta de interesse em transmitir a experiência de geração em geração; e o fato de que todos os objetos culturais não mais são cultuados, nem necessitam da tradição popular (BENJAMIN, 1985, 114). Também fala de provérbios e da loquacidade com que se narravam os antigos acontecimentos. Apresenta, portanto, que o que havia sido experimentado nas comunidades de outrora já está em vias de declínio. Isso significa que a experiência não é mais invocada como antes. Após a primeira guerra mundial, o retorno dos homens combatentes não permitia a eles a capacidade de historiar o que Ihes aconteceu. Benjamin explica esse fato por terem sido as guerras fatos desmoralizantes e degradantes corporalmente, em suma experiências horríveis e inúteis a todos os seus experimentadores, e 
portanto incomunicáveis, na perspectiva da narração. Vivemos uma época que viu diversas faces da falência de valores, porque já se inicia, a todo vapor, a sobreposição da técnica sobre a capacidade do homem de narrar o que se the sucede; e, portanto, de utilizar a sabedoria na sua narrativa ao invés de vangloriar-se como atualmente, dos bens culturais da técnica para os quais nenhum esforço pessoal foi despendido, e dissipando, com isso, o encanto de poder narrá-los integralmente. Consequência imediata disso é a miséria espiritual. Benjamin alerta tentando resgatar as artes para reanimar a tradição totalmente esquecida na guerra e na miséria. Ele tenta reerguer os valores culturais como base para condutas humanas. Hoje eles só servem para confessar a nossa pobreza (BENJAMIN, 1985, 114). A experiência é subalternada frente à técnica atual e ao desenvolvimento desenfreado do capitalismo, na sociedade moderna. Assim, não podemos mais enxergar homens realmente construtores e criadores, que experimentem, nas suas vidas, aquilo em que o mundo lhes impacta, sem que nenhuma força ou determinação exterior possa impedir isso.

Pode-se afirmar que o impacto dessa constatação sobre o homem é possível paralelizar-se ao que Benjamin tentou estabelecer com sua filosofia, em confronto direto com o que the precedeu. Segundo Cidiane Lobato (LOBATO, 2011, 117), Benjamin propõe uma ontologia que rompe com toda a metafísica antiga, medieval e moderna: não mais tratando-se da investigação de conceitos, muito menos aceitando a linguagem conceitual, ele resgata uma linguagem primordial, que dá primazia à construção de ideias, reelaborando e salvando, nesse processo, experiências que comunicam e permitam o resgate do permanentemente novo. Benjamin vê novos rumos naquele homem que ousa usar a linguagem como um eterno criativo, que não enrijeceu o seu conhecimento em mitos e ideias meramente transmissíveis, mas recriáveis. No entanto, essa defesa vigorosa do novo se confronta com a forte ascendência capitalista, que em si mesma não preza a perspectiva de novidade construída com ideias e a criatividade humanas.

Há dois fatores, um positivo e outro negativo, que podem ser apontados nessa guinada capitalista. Fruto da sociedade burguesa, a nova cultura, 
segundo Benjamin, atribuiu à experiência dos homens a liberdade de desfrutar o que ela thes oferecia, mas ao mesmo tempo os transforma em seres incapazes de narrar o que acontece consigo próprios; pois o que eles conseguem narrar tão somente se restringe às experiências determinadas pela sociedade capitalista em que vivem, que é repleta de mecanismos para entretê-los, mas que apaga e anula a sua história propriamente humana. Isso não ocorre apenas no nível da experiência cotidiana, como também na formação cultural dos indivíduos. De outro lado, a nova cultura pode ser vista como a consolidação máxima da negligência humana através dos tempos, na medida em que traz condições para que o homem viva a partir dela. Se desse diagnóstico resta alguma saída é o que será visto na próxima seção, que remonta à relação criativa implicada nas duas capacidades humanas.

\section{O definhamento da comunicação criativa da narrativa frente ao capitalismo}

O Narrador, diferente de Experiência e Pobreza ${ }^{1}$ exprime a ideia de narrativa diretamente vinculada à tradição oral. Ela exprimia a riqueza da experiência e alavancava a capacidade de criação durante a própria narração. A inspiração que tínhamos para contar histórias era útil para ensinar e aconselhar,, daí a riqueza narrativa. Mas, como já foi abordado, o romance se contrapõe à narração, na medida em que tolhe, desses processos enriquecedores da alma humana,: a liberdade que caracterizava o ouvinte de uma narração, depois absolutamente inviabilizada com o surgimento do romance, engolfado no extravio permanente da análise psicológica. A prioridade do romance, ao contrário, não é o contato com o artesanato típico de todo legítimo narrador, mas meramente dar sequência à atualidade.

\footnotetext{
1 "Enquanto "Experiência e Pobreza" descrevia o esfacelamento da narração tradicional numa multiplicidade de narrativas independentes, ao mesmo objetivas e irreverentes, "O Narrador" coloca alguns marcos tímidos para definir uma atividade narrativa que saberia rememorar e recolher o passado esparso sem, no entanto, assumir a forma obsoleta da narração mítica universal [...]" (GAGNEBIN, 1999, p. 62).
} 
Benjamin começa a obra O Narrador anunciando que o ato de narrar é uma consequência oralmente comunicável. Dada a ausência do narrador, a sua atualidade está quase morta, de tão exígua em distância, e a sua necessidade, consequentemente, também (BENJAMIN, 1985, 199). Ele elege Nikolai Leskov como o narrador que consegue trazer da narração o que nela foi perdida: o intercâmbio de experiências entre ouvinte e narrador - a de experienciar o tradicional, que está em desuso na contemporaneidade. Segundo Jeanne Marie Gagnebin,

enfim, a expressão privilegiada dessa experiência tradicional é a palavra do moribundo, não porque ele teria qualquer saber secreto pessoal a nos revelar, mas muito mais porque, no limiar da morte, ele aproxima, numa repentina intimidade, nosso mundo vivo e familiar deste outro mundo desconhecido e, no entanto, comum a todos (GAGNEBIN, 1999, 58).

É notório que há uma inflexão quanto à expressão da experiência tradicional. Ela perde a sua potencialidade de se revelar e nos conduzir a um mundo desconhecido. Já não podemos perceber-nos originários e relacionados com ele: com a história e com a tradição que nos integrava e remetia a sermos quem somos; resta-nos apenas um momento para psicologicamente avaliar e observar quem somos. Nada muito amplo. Ainda segundo Gagnebin, "Essa interiorização psicológica é acompanhada por uma interiorização especificamente espacial: a arquitetura começa a valorizar, justamente, o 'interior'. A casa particular torna-se um refúgio contra um mundo exterior hostil e anônimo" (GAGNEBIN, 1999, 59). A autora refere-se a uma das diversas revoluções da vida humana que o capitalismo provocou. Evidentemente, o capitalismo não está comprometido com a narrativa tradicional, o que o tornaria desatento de seus métodos e objetivos; ele opera segundo a sua lógica, que não prima pela história propriamente humana. Mas esta, em contrapartida, é desprezada em vista da atenção à própria psicologia por parte de cada indivíduo, outra forma de empobrecimento da narrativa e da experiência.

Contraditoriamente, cada vez menos é possível, de um lado, transmitir o que ocorre no mundo exterior e, de outro, adentrar na complexidade da reflexão histórica que nos é própria e nos caracteriza. Pois não é possível 
compatibilizar a orientação de condutas e normas morais com notícias dispersas e pontuais que são pinçadas na realidade e trazidas à tona diariamente da mesma forma que é impossível compatibilizar a criação e narração com uma obra do gênero romance, que não está disponível a transmitir ações humanas a serem recriadas conforme o ouvinte ou o leitor tomam contato com isso. Os livros produzidos atualmente, enfim, seguem a mesma lógica: comunicam de modo parco, posto que se submetem a transmitir o que atualmente está em voga e é lançado. O resultado disso é a permanência da complexidade das ações humanas - em extrema dispersão e superficialidade - à subordinação de tanta fugacidade imposta pela dinâmica de atividades típicas do capitalismo reinante no mundo.

Voltando aos valores do passado como constituintes do narrador, Benjamin introduz a existência de dois grupos arcaicos e fundamentais de narradores, para tanger a presença da figura do narrador e para mostrar que é possível, sim, haver comunicação entre narrador e ouvinte da narração de modo não letárgico, mas dinâmico e criativo. São eles: o camponês sedentário e o marinheiro comerciante. Mas afirma, cuidadosamente, que o reino da narração abrange a história inteira, a partir do seu arcaísmo, passando pelo período medieval e chegando aos tempos modernos, e faz interpenetrar, soberana e necessariamente, quaisquer aspectos e ocorrências que se sucederam nesses períodos: o seu alcance histórico, portanto, compreende uma liberdade inigualável (BENJAMIN, 1985, 216). Foi, com efeito, no sistema corporativo medieval onde Benjamin viu que os indivíduos detinham nitidamente o saber do passado, baseado no saber de terras distantes, como o saber prático de um trabalhador sedentário.

O senso prático confere grande valor à narrativa e pertence à sua natureza; a prática utilitária que ele permite é o seu maior valor, sobretudo porque faz com que nós observemos condutas morais ou normas de vida que muitas vezes não levamos em consideração no cotidiano em que vivemos. É daí que advêm os conselhos dados e sua importância: uma importância que apenas se registra se nós soubermos dá-los, por meio da narrativa. Benjamin diz que tomar conhecimento disso depende estritamente da comunicação da 
forma como aconselhamos: se queremos fazer uma sugestão da história, por exemplo, precisamos primeiramente saber contar a história, e o conselho segue espontaneamente essa forma (criativa) de contá-la (BENJAMIN, 1985, 215). A sabedoria é, portanto, para Benjamin, aquilo que resgata a substância da existência, das experiências. A narrativa consegue transmiti-la a outrem, posto que há uma verdade aí implícita que pode infinitamente ser remodelada e que é a sua maior razão de ser. O conselho, por sua vez, seria a ação executada nesses termos, e teria como base tal sabedoria. Mas isso é gradativamente perdido com a decadência da narrativa, cada vez mais está ofuscada pela precedência das forças produtivas do capitalismo.

Para apontar motivos históricos dessa decadência, Benjamin (BENJAMIN, 1985, 201) cita alguns fatos e os explica. O primeiro é o surgimento e a difusão do romance. Enquanto a narração se vale da experiência, contada pelo próprio narrador ou relatada por terceiros, o romance, diferentemente, não tem como princípio relatar nada: o romancista define-se como alguém que, isoladamente, não se guia pela sabedoria, pois nem escreve para receber conselhos nem sabe dá-los; isto é, o romance interioriza o homem, que, afundado nisso, nem está propenso a dar conselhos nem, portanto, da sua sabedoria se vale. Entretanto, o Decameron, sendo um exemplo histórico da narração oral, possui uma articulação com o senso prático próprio da narrativa. O segundo é a consolidação da informação, que é muito influenciada pelo domínio do capitalismo; porque é mais conveniente e importante a lide com os acontecimentos próximos do que com os longínquos para o sistema não só capitalista, mas da própria forma de conhecimento que tem credibilidade: a ciência. Tanto os acontecimentos próximos como as informações imediatas são necessários a esse sistema, que precisa, ademais, de verificação imediata das informações. O caráter de imediato dessa informação é indispensável tanto quanto o de plausibilidade, pois o capitalismo necessita disso para cada vez amplificar-se no mundo e não nos abrir a perspectiva, nem a necessidade, da busca por explicações que advenham da nossa própria experiência, visto que estas são apagadas ou estão embutidas irrisoriamente na própria informação veiculada. Em suma, a amplitude da 
narração é anulada na informação. E, ao contrário do valor que a informação recebe, no capitalismo, na narrativa, o valor dela só aparece no momento em que algo de novo ocorre na narrativa; esta se desenvolve por si mesma conforme o seu poder de explicar de forma, a mais diversa, tal ou qual a experiência. As narrativas são sempre capazes dessa diversificação causada tanto em quem a relata como em quem a ouve.

Outro aspecto apontado por Benjamin para aduzir à decadência da narrativa são as sutilezas psicológicas que fazem memorizar ou entediar 0 ouvinte. A psicologia, nesse caso, interfere na experiência plena que é contada e assimilada através do tédio, causando-nos uma distensão psíquica: "o tédio é o ponto mais alto da distensão psíquica" (BENJAMIN, 1985, 215). Essa é uma consequência direta do esquecimento de nós mesmos e da dispersão absoluta em relação ao que ouvimos; em uma perspectiva de arte artesanal, ao contrário, podia-se verificar que a narrativa clássica mergulhava na vida de cada ouvinte, não só porque as histórias eram contadas e recriadas, mas também porque se compunha uma cumplicidade de experiências. Em contraponto com as desastrosas consequências que são visíveis nos tempos modernos, nomeadamente o tédio, Benjamin, então, reaviva o esplendor do ritmo da história quando contada, ou seja, traz o fascínio do alheamento e da imersão na história, de tal modo que ele ganhe espontaneamente o dom de infinitamente remontar àquilo que foi tecido e de mantê-lo sempre ativo e presente. Trata-se do mergulho na sua própria vida, para a qual o homem traz suas próprias qualidades e características quando narra, o que impacta o ouvinte da mesma forma, fazendo-o atento não só por estar nessa condição, como também porque o afeta o que está sendo-lhe narrado. É impossível, portanto, pensar em cultivo de uma vida rica de experiência sem isso. Mas a decadência da arte de narrar ocorre porque o mundo industrializado nem precisa da tradição oral nem de histórias muito longas para subsistir. Como transmissor do estreitamento do que se concebe por conhecimento, nas relações do capital, o romance é de fato um grande autor dessa perda e pobreza. 


\section{O definhamento da narrativa na contemporaneidade, a partir do romance}

Benjamin introduz uma reflexão sobre a morte, a partir do momento em que aponta para o fato de que a sabedoria está em extinção, ou pelo menos em decadência (BENJAMIN, 1985, 207). Isso se define pela retirada permanente da experiência da vida que o discurso vivo da narrativa mantinha; No romance o que é retirado é, sobretudo, a parte transmissível daquilo que é vivido, cuja autoridade reside na naturalidade como caráter próprio da história. Mas ela, a morte, é aquilo que não pode estar presente ou visível na sociedade burguesa, que higieniza as imagens e as torna reprimidas quando é necessário, a exemplo do que ocorre quando alguém está velho ou doente, indo a hospitais e sanatórios. Segundo Benjamin, no entanto, é nesse momento da morte que se estabelece a autoridade de poder ser narrado o que é inesquecível e transmissível: a autoridade tem como função remontar aquilo que já foi vivido, mas nem por isso está morto, visto que a morte é sempre um indicativo de que podemos conhecer a história e nós mesmos a partir do que escutamos do narrador (BENJAMIN, 1985, 207-208). Assim sendo, a morte é aquilo que autoriza e torna mais possivelmente sábio aquilo que o narrador pode contar, porque ela confere a ele a autoridade de toda a história natural.

Entretanto, é muito diferente essa história natural e a autoridade com que o narrador faz a narrativa da história romantizada. Segundo Roland Barthes, "não se trata do prazer do strip-tease corporal ou do suspense narrativo. Em ambos os casos, não há rasgão, não há margens; há uma revelação progressiva [...]"(BARTHES, 1987, 15). A narrativa, assim, nos romances clássicos, como os de Balzac e Tolstoi, trazem, em si, uma espécie de mimese (repetição) enfraquecida, caracterizada por uma baixa de intensidade e por uma falta de integridade no texto; tudo porque o leitor, nesse caso, está, mormente, preocupado com os momentos de êxtase da história e com o fim dela, com o seu enigma a ser resolvido ou o destino que os seus personagens terão: eis a mera satisfação romanesca, desprovida do prazer com os acontecimentos e com o suspense narrativo. Passa-se ao largo do 
strip-tease acima referido, sequer reconhecendo-o. A fruição das histórias românticas é reduzida de modo drástico. Isso é uma morte, igualmente: somos psicologicamente levados à concretude da história, ao que ela tem a dizer para aplacar cada um de nossos sentimentos pessoais, mas pouco estimulados a mergulhar, como na narrativa, em nós mesmos como seres históricos e culturais.

Entre todas as formas épicas de contar história, Benjamin elege a crônica como sendo a mais consagrada. Diferentemente do historiador, que apenas escreve a história, o cronista a narra; o historiador não segue representações, como os cronistas o fazem; sobretudo as representações medievais, que deram origem à historiografia moderna. Mais ainda: o cronista envolve todo o mundo quando narra uma história, ao invés de fazer explicações pontuais e não verificáveis. A crônica, não procedendo por nenhum método científico ou historiográfico, está comprometida não com os fatos determinados, mas com que a cultura e a história humanas admitam-se como fluxo contínuo das coisas, em uma perspectiva de permanente criatividade (BENJAMIN, 1985, 209). A nossa história e cultura tendem, por isso mesmo, à constituição de uma natureza que guarda os nossos traços, seja porque teremos uma memória mais rica com a crônica, seja porque nos sentiremos harmonizados conosco mesmos, ingenuamente, no ato de narrar e em meio à narrativa.

Morte e memória possuem, nesse sentido, uma relação intrínseca: a memória, quando abrangente, abrange tudo que diz respeito a uma coisa, compondo o narrador, assim, a sua história. A memória vem acompanhada do desaparecimento dessas mesmas coisas que são narradas, um desaparecimento que representa o poder da morte. Acerca disso, Benjamin dá o exemplo da épica poética, mais precisamente de Mnemosyne, a deusa da reminiscência, a sua maior representante. Sendo a reminiscência a forma mais sublime de produzir-se efetivamente a história (porque ela é o meio pelo qual podemos inventá-la e reinventá-la), explica Benjamin que tanto a forma épica, tece na tradição um sentido mais amplo e, nesse sentido, dá uma lógica a todos eles, reunindo-os entre si e os pondo à disposição na inteligência tanto 
do narrador como do ouvinte (BENJAMIN, 1985, 211). Além de abarcar magistralmente todas as histórias e criar, assim, uma cultura reminiscente, a reminiscência inova e cria uma nova história, na medida em que a narrativa acontece sempre que ela é recontada. Fundida à memória, a reminiscência promove a indefinição e a variação permanentes, enquanto que, no romance, o narrador atém-se a um objeto ou fato específico. No romance, apenas a morte é tema central, pois ele próprio se designa por matar, ou pelo menos fazer decair, a criatividade humana, na própria história que nos concerne.

O romance difere também da narrativa, uma vez que aquele busca o "sentido da vida" - limitando-se a que isso seja a única coisa despertada no fim da história que conta -, enquanto a narrativa não está preocupada com 0 sentido da vida, pois integra inúmeros e passageiros sentidos enquanto ela é feita. No fim do romance, o leitor pode até procurar o tal sentido, mas solitariamente; enquanto que, no caso da narrativa, sempre haverá a companhia do ouvinte, a começar por quem narra. Pois, segundo Benjamin, o leitor de um romance não passa de um destruidor do fluir da história, da qual se apodera como se tivesse propriedade para tomar e governar a sua substância: "sim, ele destrói, devora a substância lida, como o fogo devora lenha na lareira. A tensão que atravessa o romance se assemelha muito à corrente de ar que alimenta o reanima a chama" (BENJAMIN, 1985, 213). O romance, de um lado, redireciona a nossa forma de lidar com a história; de outro lado, faz recair em uma rememoração apenas de si mesmo o indivíduo que o lê, ostentando-se incapaz - quando lida, por exemplo, com a morte de alguém - de sair da última fase de sua vida, como se a rememoração apenas tivesse sentido, se feita a partir de sua própria vida. Ou seja, é como se o sentido fosse revelado apenas com a morte. E há o objetivo principal do leitor do romance: é contar para ele uma morte que, como não concerne a ele, o tranquiliza.

Para Susana Lages, o romance evoca uma nova perspectiva na relação entre texto e leitor: a relação de melancolia, com a qual, no ato individual da leitura, prevalece a dimensão profundamente subjetiva; em outras palavras, prevalece a busca de um reflexo entre o romance e eu mesmo (LAGES, 2002). 
A felicidade sempre haverá na narrativa, segundo Susana:

a ideia de felicidade como possibilidade resgatável pela rememoração e a projeção de um momento de plenitude sem precedentes, que indica uma forma diversa de viver o tempo, uma forma pela qual, paradoxalmente, quanto mais se imerge nele, mais ele se confunde com alguma forma de eternidade, de cessação do tempo e, portanto, no limite, de morte (LAGES, 2002, 138).

Abre-se a possibilidade do que é propriamente novo na alma humana, uma vez que é possível que a nossa linguagem e memória repitam a sua potencialidade incessantemente no futuro, ainda que uma tristeza também seja própria dela: a tristeza advinda de que a narração acabou. A única felicidade que o romance nos traz é a riqueza da história em si que se dispõe a contar; ele nunca nos remete à humanidade como história. É por isso que a tristeza é, na mesma medida, inevitável. O romance é tão insuficiente como remonte ao que nos é próprio que não pode deixar de causar melancolia, tanto como a sensação de estarmos fadados à extrema infinitude do círculo, ao percorrer do qual estamos destinamos; estamos destinados, portanto, à falta do nosso organismo cultural que a narrativa tradicional nos oferece. A melancolia é, na verdade, fundadora de uma referência, na qual nos agarramos e nos prendemos, pois, em detrimento da liberdade para criar e recriar a história que a narrativa clássica oferece.

A narrativa clássica, muito distante do romance moderno, tem por natureza a capacidade de adequar-se a qualquer fenômeno e acontecimento, pois nela tudo é voltado à experiência e atinge tudo que for próprio à vida humana: sentimentos, decisões e valores. Benjamin considera que a flexibilidade da narrativa, primordialmente expressa pelo conto de fadas, atinge um grau tão alto que podemos mover nossa experiência como quisermos, tanto mais porque ela sempre envolve a coletividade; a morte, nesse caso, não representa nada de tão esplendoroso, visto que não traz impedimento à continuidade rica da experiência individual e coletiva que nos integra (BENJAMIN, 1985, 215). A morte não é entendida como uma barreira frente a qual nada mais pode ser feito, mas como mais um alimento a contribuir com a diversificação do mergulho na experiência humana que faz a arte de narrar. E o conto de fadas, por sua vez, é tão consagrado como primeira e mais valorosa 
narrativa que nos liberta para transformar o significado do mundo com a mesma flexibilidade que uma criança o faz: com o conto de fadas faz perceber, ademais, que a natureza está unida a nós, não apartada. E o despertar dessa percepção gera felicidade, tanto na criança como no adulto. Aí, então, descobre-se a profundidade do mundo imaginário e a complexidade que nele sempre existe, por ser composto à base de características e experiências humanas.

\section{Conclusão}

Ficou exposto que o homem, na contemporaneidade, encontra-se em uma incapacidade de invenção e criação. A história, não enquanto narrativa, mas enquanto ação e efetivação humana, atualmente é perpassada de esterilidade e lembrança constantes, tal como no romance, cujo personagem principal se ajuda sem que ao leitor consiga ajudar. Assim essa lembrança relíquia secularizada - é improdutiva, portanto, porque não recobre nada além de si mesma, além de ser infértil no que tange às ações autenticamente humanas. O romance, desta forma, não oferece nenhuma perspectiva de transmissão de sabedoria; oferece, no entanto, um referencial psicológico no qual a leitura da história chega: à melancolia. E o homem, nessa medida, está fadado a não narrar o que é experiência, pois nada possui para narrar senão a sua repetição sofrida e auto-referida enquanto história, repetição decadente, muito favorável ao capitalismo reinante na sociedade, que impõe que tal repetição se afixe efetivamente como sendo a pauta da vida humana: a negação da história do homem em prol da afirmação da informação sobre os acontecimentos próximos, no lugar de sua cultura vasta, distante, longínqua e que pode, pela narrativa, ser falada e criada com base na eterna disposição que caracteriza a sabedoria pelas tradições.

Essa cultura propriamente humana, alavancada, recoberta e sustentada pela narrativa, garantiria ricamente a memória e a linguagem do homem, porque estaria em suas mãos o passado e a capacidade de criar o presente de forma permanente, através da repercussão dos acontecimentos que a vida 
nunca deixou de reservar. No entanto, como a experiência - algo que se transmitia através de gerações - foi abolida, também o foram as narrativas que serviam de exemplos e ensinavam os homens. E assim, segundo Benjamin, a tradição deixa de ser transmitida, por conseguinte, o que há agora é apenas um vazio presente, uma separação da cultura e a negação do homem histórico que havia antes nas comunidades artesanais. Junto a ele, aparece o romance moderno, aquele que proporcionou uma diferença empobrecedora em comparação à narrativa clássica, que instaurava um reflexo entre homem e texto ou homem e história. A pobreza da experiência passa a ser 0 esquecimento quase completo de uma história viva que transpassa e abastece a narrativa permanentemente: antes, a felicidade de recriar os tempos; agora, com o romance moderno, a tristeza, e ilusão, porque o homem crê que a história realmente se encerra com o fim da leitura ou de uma descoberta cujo estímulo é dado pelo fio condutor do romance. No romance os acontecimentos históricos são reduzidos a acontecimentos promovidos por personagens na história romântica, não tendo nada disso a necessidade de remontar à cultura e à história humanas.

\section{REFERÊNCIAS}

BENJAMIN, Walter. Prefácio. Jeanne Marie Gagnebin. "Walter Benjamin ou a história aberta" in:_Magia e Técnica, arte e política: ensaios sobre literatura e história da cultura. (Obras escolhidas v.1). Trad. Sérgio Paulo Rouanet, 1. ed., Brasiliense, 1985. P. 7-19.

"A crise do romance - sobre Alexanderplatz de Döblin".In:_ Magia e Técnica, arte e política: ensaios sobre literatura e história da cultura. (Obras escolhidas v.1). Trad. Sérgio Paulo Rouanet, 1. ed., Brasiliense, 1985. P. 54-60.

. "Experiência e Pobreza" in:_Magia e Técnica, arte e política: ensaios sobre literatura e história da cultura. (Obras escolhidas v.1). Trad. Sérgio Paulo Rouanet, 3. ed., Brasiliense, 1985. P. 114-119.

. "O Narrador" in:_Magia e Técnica Arte e política. (Obras escolhidas v.1). Trad. Sérgio Paulo Rouanet, 1. ed. Brasiliense, 1985, 197-221. 
BARTHES, Roland. O prazer do texto. Trad. J. Guinsburg. São Paulo: Perspectiva, 1987.

GAGNEBIN, Jeanne Marie. História e Narração em Walter Benjamin. São Paulo: Editora Perspectiva, 1999.

LAGES, Susana. Walter Benjamin: Tradução e melancolia. São Paulo: EDUSP, 2002.

BONDÍA, Jorge Larrosa. "Notas sobre a experiência e o saber da experiência" in:__Revista Brasileira de Educação. n. 19, ján/fev/mar/abr. 2002.

LOBATO, Cidiane. "Benjamin e a questão da experiência" in:_Cadernos Walter Benjamin - Periódico N. 7 - Julho a Dezembro de 2011, acessível no site: www.gewebe.com.br 